\title{
Diagnosis and management of bovine babesiosis outbreaks in cattle in Punjab state
}

\author{
Mandeep Singh Bal ${ }^{1}$, Vishal Mahajan ${ }^{1}$, Gursimran Filia ${ }^{1}$, Paramjit Kaur ${ }^{2}$ and Amarjit Singh ${ }^{1}$ \\ 1. Animal Disease Research Centre, Guru Angad Dev Veterinary \& Animal Sciences University, Ludhiana, Punjab, India; \\ 2. Department of Veterinary Parasitology, Guru Angad Dev Veterinary \& Animal Sciences University, Ludhiana, \\ Punjab, India. \\ Corresponding author: Gursimran Filia, e-mail: harpalfilia@rediffmail.com, \\ MSB: bal_epi@rediffmail.com, VM: mahajanv17@gmail.com,PK: paramvet53@rediffmail.com, \\ AS: amarjitsingh64@gmail.com \\ Received: 10-05-2016, Accepted: 02-11-2016, Published online: 06-12-2016
}

doi: 10.14202/vetworld.2016.1370-1374 How to cite this article: Bal MS, Mahajan V, Filia G, Kaur $P$, Singh A (2016) Diagnosis and management of bovine babesiosis outbreaks in cattle in Punjab state, Veterinary World, 9(12): 1370-1374.

\begin{abstract}
Aim: The aim of the present study was to diagnose severe outbreaks of bovine babesiosis in Punjab state, in the year 2015 and to suggest control and preventive measures to animal owners.

Materials and Methods: Mortality of animals was recorded in two cattle herd comprising a total of 465 cattle in Sangrur $(\mathrm{n}=125)$ and Faridkot $(\mathrm{n}=340)$ districts. There was a history of purchase of animals at one farm. 23 blood samples were collected from diseased $(n=15)$ and healthy animals $(n=8)$ for hematological analysis, parasitological, and polymerase chain reaction (PCR)-based diagnosis. Ticks were also collected from animals for identification.

Results: Out of 465 cattle at risk, 28 were critically ill and 14 died of disease with morbidity, mortality, and case fatality rate of $6.02 \%, 3.01 \%$, and $50.00 \%$, respectively. Clinical signs and necropsy findings were suggestive of babesiosis. Ticks collected from both the outbreaks were identified as Rhipicephalus (Boophilus) microplus. Thin blood smears from infected animals (especially with clinical sign of hemoglobinuria) were found positive for Babesia bigemina organisms; however, molecular diagnosis (PCR) further confirmed the disease. Animals were successfully treated with diminazene aceturate, hematinics, and antipyretics.

Conclusions: Two fatal outbreaks of babesiosis in cattle were diagnosed with application of conventional parasitological, hematological, and molecular diagnostic techniques. PCR was found to be far more sensitive in detecting the disease, especially in latent infections. Animal owners were advised to follow quarantine measures before mixing new animals in the herd and strategic acaricidal treatments for effective tick control.
\end{abstract}

Keywords: Babesia bigemina, cattle, outbreaks, parasitological diagnosis, polymerase chain reaction.

\section{Introduction}

Bovine babesiosis caused by intraerythrocytic hemoprotozoa Babesia bigemina is a tick-borne disease affecting the bovines in tropical and subtropical parts of Africa, Australia, America, and Asia including India. Walker and Edward [1] first time reported babesiosis in India. Annual economic losses to livestock due to babesiosis in India are estimated to be about 57.2 million US dollars [2].

Punjab (situated in the North-western part of India), the third highest milk producing state of the country, has a total of 6.7 million cattle and buffalo population as per the $18^{\text {th }}$ livestock census (http:// www.husbandrypunjab.org/pages/livestock.html). The climate conditions of Punjab state are conducive for tick vector survival. Clinically, disease has been characterized by anemia, fever, hemoglobinuria, and

Copyright: Bal, et al. Open Access. This article is distributed under the terms of the Creative Commons Attribution 4.0 International License (http://creativecommons.org/licenses/by/4.0/), which permits unrestricted use, distribution, and reproduction in any medium, provided you give appropriate credit to the original author(s) and the source, provide a link to the Creative Commons license, and indicate if changes were made. The Creative Commons Public Domain Dedication waiver (http://creativecommons.org/ publicdomain/zero/1.0/) applies to the data made available in this article, unless otherwise stated. in many cases death [3]. The crossbred cattle exhibited higher rate of susceptibility than zebu and buffaloes, which mainly act as carrier [4]. In buffaloes, the clinical symptoms reported are hemoglobinuria, anorexia, suspended rumination, reduced milk yield, and depression [5-7]. The calves up to 9-12 months of age are generally resistant due to inverse age resistance, but the clinical symptoms of babesiosis in neonatal calves were inability to suckling, high fever, coffee color urine, jaundice, and deep shallow respiration $[8,9]$.

The classical microscopic examination of Babesia piroplasms in Giemsa stained thin blood smear is a gold standard test that is relatively cheap and quick method; however, in chronic infection, it has low sensitivity and usually fails to detect carrier animals [10].

In Indian scenario, there are sporadic reports on diagnosis of bovine babesiosis by conventional parasitological methods [11-13]. Serological tests are used for large-scale epidemiological studies. However, they fail to detect early infection. Alternatively, polymerase chain reaction (PCR) has been widely used for the detection of Babesia parasites owing to its high specificity and sensitivity $[14,15]$. The present reports 
depict the confirmatory diagnosis of two severe outbreaks of bovine babesiosis based on conventional microscopy and PCR targeting the small subunit ribosomal RNA (SSU rRNA) sequence of B. bigemina and its management.

\section{Materials and Methods}

\section{Ethical approval}

The manuscript is related to the investigation of outbreaks based on the urgent request by the livestock farmers/animal husbandry department official to rule out the cause. Hence it is not the experimental study, as per institution guidelines ethical approval is not required.

\section{Animals and sampling}

This department received requests from local veterinarians/farmers regarding mortality of animals (cattle) with symptoms of high fever and red/coffee-colored urine in Sangrur and Faridkot districts of Punjab. The two cattle herd comprising total 465 cattle in Sangrur $(n=125)$ and Faridkot $(n=340)$ where mortality of animals was recorded. Animals of both of the farms were stall-fed. Deworming and routine vaccination practices were followed at farms. Tick infestation was also observed in animals. Twenty-three blood samples were collected from diseased $(n=15)$ and healthy animals $(\mathrm{n}=8)$ for hematological analysis, parasitological, and molecular diagnosis. Approximately $5 \mathrm{ml}$ of blood sample from jugular vein was collected in ethylenediaminetetraacetic acid coated and plain vacutainers from each animal. Thin blood smears were prepared and stained with Leishman stain. There was a history of purchase of animals at one farm in district Sangrur. Outbreaks were reported in the months of June (Sangrur) and July (Faridkot).

\section{Sample analysis}

Hematological parameters, namely, total leukocytes count $\left(10^{3}\right.$ cells $\left./ \mu \mathrm{L}\right)$, hemoglobin $(\mathrm{Hb}, \mathrm{g} / \mathrm{dL})$, packed cell volume (\%), differential leukocyte count $(\%)$, and platelets (Plt, $10^{3}$ cells $/ \mu \mathrm{L}$ ) were evaluated in parasitologically positive animals (Group I, $n=7$ ), parasitologically negative (Group II, $\mathrm{n}=8$ ), and healthy control (Group III, $\mathrm{n}=8$ ) animals. Ticks were collected from animals of both the farms, mounted in Canada balsam after clearing as per standard procedure and identified microscopically according to keys given by Miranpuri [16].

Genomic DNA was extracted from all the collected blood samples using HiPurA ${ }^{\mathrm{TM}}$ blood Genomic DNA MiniPrep Purification Spin Kit as per the given protocol (HiMedia Laboratories, India). PCR was carried out on the DNA targeting the SSU rRNA of $B$. bigemina [17]. PCR was carried out in reaction mixture $(25 \mu 1)$ contained $12.5 \mu 1$ of KAPA $2 \mathrm{G}^{\mathrm{TM}}$ Fast HotStart Ready Mix (2× containing KAPA 2G Fast HotStart DNA polymerase, KAPA 2G Fast HotStart PCR buffer, $0.2 \mathrm{mMdNTP}$ each, $1.5 \mathrm{mM} \mathrm{MgCl}_{2}$ ), $1.5 \mu \mathrm{l}$ of $10 \mathrm{pmol}$ primers each, $4.5 \mu \mathrm{l}$ of NFW, and
$5 \mu 1$ of DNA template. Amplification was carried out with cycling conditions: initial denaturation at $95^{\circ} \mathrm{C}$ for $5 \mathrm{~min}, 30$ cycles of denaturation at $95^{\circ} \mathrm{C}$ for $30 \mathrm{~s}$, annealing at $57^{\circ} \mathrm{C}$ for $1 \mathrm{~min}$, extension at $72^{\circ} \mathrm{C}$ for $1.5 \mathrm{~min}$, and final extension at $72^{\circ} \mathrm{C}$ for $10 \mathrm{~min}$ in a thermocycler (Eppendrof, Germany). The amplified PCR products (689 bp) were visualized using $1.5 \%$ agarose gel electrophoresis (Syngene, UK).

\section{Treatment}

Treatment of infected animals was carried out and control measures were suggested to animal owners. Officials of animal husbandry department/local veterinarians were also informed about the outbreaks for implementation of control measures to prevent the spread of disease among other animals in the surrounding areas.

\section{Statistical analysis}

Data were analyzed by analysis of variance using SPSS software.

\section{Results}

Out of total 465 cattle at risk (125 Sangrur and 340 Faridkot), 28 (12 Sangrur and 16 Faridkot) were critically ill and 14 (6 Sangrur and 8 Faridkot) died of disease with morbidity, mortality, and case fatality rates of $6.02 \%, 3.01 \%$, and $50.00 \%$, respectively. Major clinical symptoms observed in affected animals were pale mucous membranes, jaundice, increased respiratory rate, hemoglobinuria, and fever. Moderate to heavy tick infestation was observed in animals (Figure-1). Ticks collected from both the outbreaks were identified as Rhipicephalus (Boophilus) microplus.

Postmortem of two animals (one at each farm) was also conducted on the spot. Necropsy findings revealed splenomegaly, epicardial hemorrhages, thick granular bile, and urinary bladder filled with coffee-colored urine (Figures-2 and 3).

Stained blood smears were examined for hemoparasites. Out of 15 diseased animals, 7 samples were found positive for piroplasms of $\mathrm{B}$. bigemina (Figure-4). Out of these 7 animals, 6 were

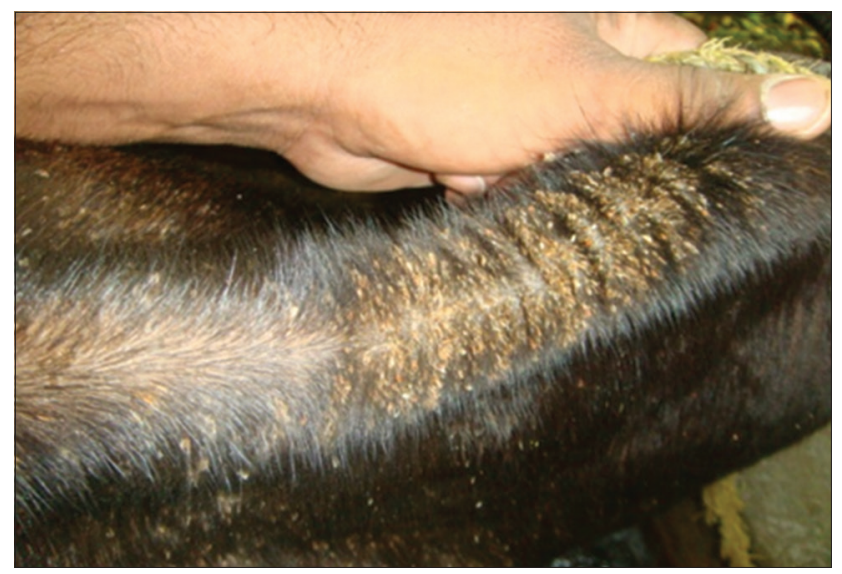

Figure-1: Heavy tick infestation. 
having history of passing red-colored urine. PCR was employed on DNA extracted from all the 23 collected samples (15 diseased and 8 healthy animals). Out of 23 samples, 13 were found positive (including 7 microscopically positive) for $B$. bigemina DNA as evident from agarose gel (1.5\%) electrophoresis showing 689 bp fragment of amplified DNA/PCR product (Figure-5). It indicates a higher sensitivity of PCR over traditional blood smear examination, especially for detecting latent infections. None of the sample from healthy animals was amplified by PCR. Thin blood smears from infected animals with clinical sign of hemoglobinuria were found positive for $B$. bigemina organisms; however, positive results by molecular diagnosis (PCR) further confirmed the disease.

The hematological parameters showed a significant $(\mathrm{p}<0.05)$ decrease in $\mathrm{Hb}(3.5 \pm 0.197 \mathrm{~g} / \mathrm{dl})$ in Group I animals (parasitologically positive) as compared to Group II $(7.79 \pm 0.252 \mathrm{~g} / \mathrm{dl})$ and Group III $(9.89 \pm 0.234 \mathrm{~g} / \mathrm{dl})$ (Table-1). The leukocytosis was observed in animals of Group I as compare to Group III animals being non significant.

Affected animals were successfully treated with diminazene aceturate, hematinics, and antipyretics. However, despite treatment, one animal died of disease due to advanced stage of disease.

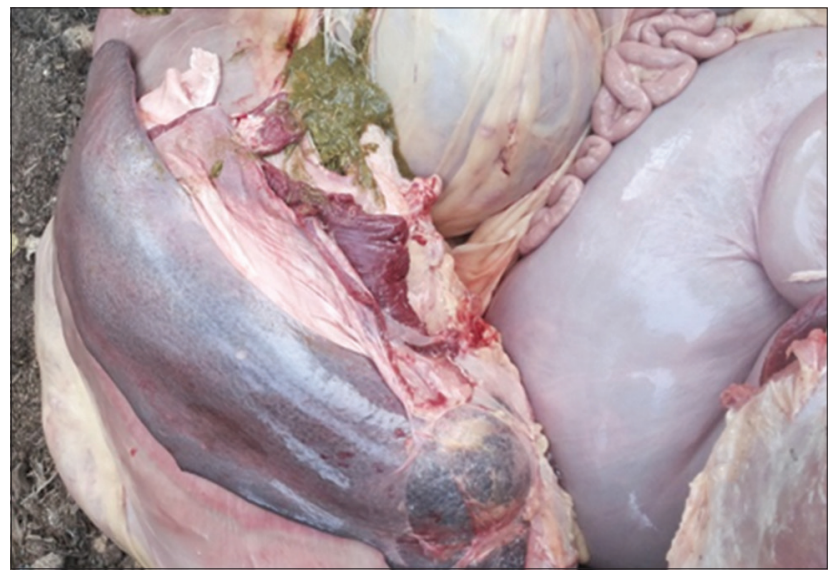

Figure-2: Splenomegaly and jaundice.

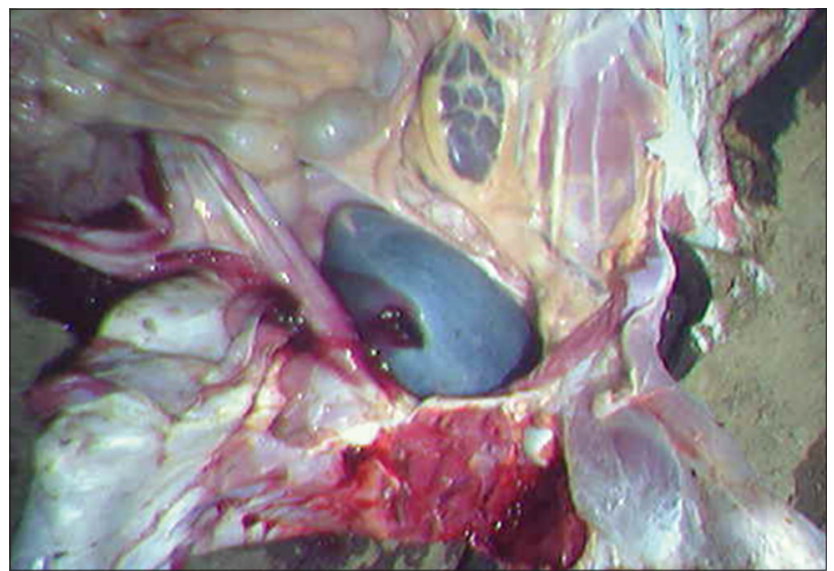

Figure-3: Red/coffee-colored urine in urinary bladder of infected cattle died of disease.

\section{Discussion}

The predominant symptoms of babesiosis; pale mucus membranes, jaundice, increased respiratory rate, hemoglobinuria, and fever were observed in parasitologically positive animals which are in agreement of published reports $[11,18,19]$.

The marked anemia and hemoglobinuria in cattle leads to the severe hemolytic process associated with the presence of Babesia piroplasms inside the erythrocytes and destruction of large number of these erythrocytes by the parasite resulting in hemoglobinemia and consequently hemoglobinuria [20].

In Punjab, the $R$. (B.) microplus is the predominant tick responsible for the disease [15] and identification of collected ticks from diseased animals supports the same. The vector widely known for the transmission of bovine babesiosis is $R$. (B.) microplus; however, transmission by Hyalomma anatolicum anatolicum was also reported [21].

Conventional diagnostic method, namely, stained blood smear examination revealed only 7 animals positive for babesiosis out of 15 diseased animals. The

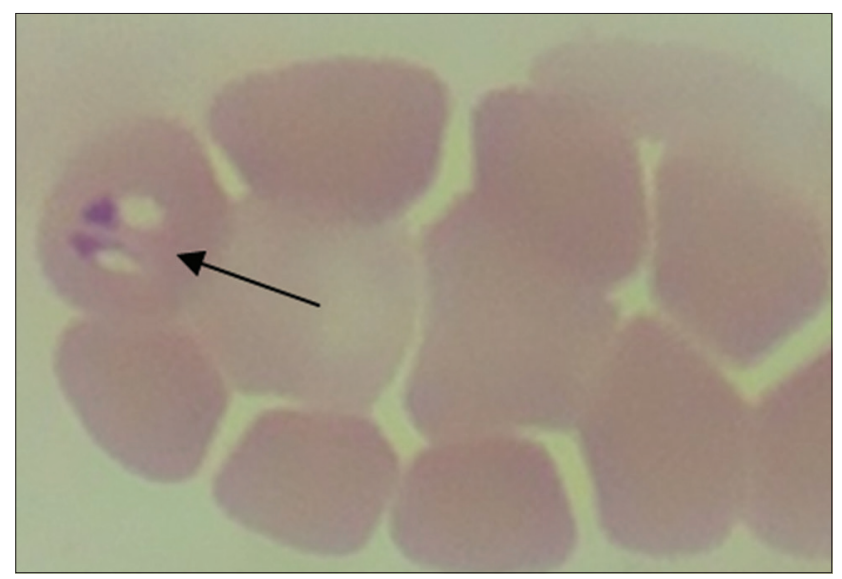

Figure-4: $B$. bigemina piroplasm in cattle blood: Leishman stained thin blood smear $(100 \times)$.

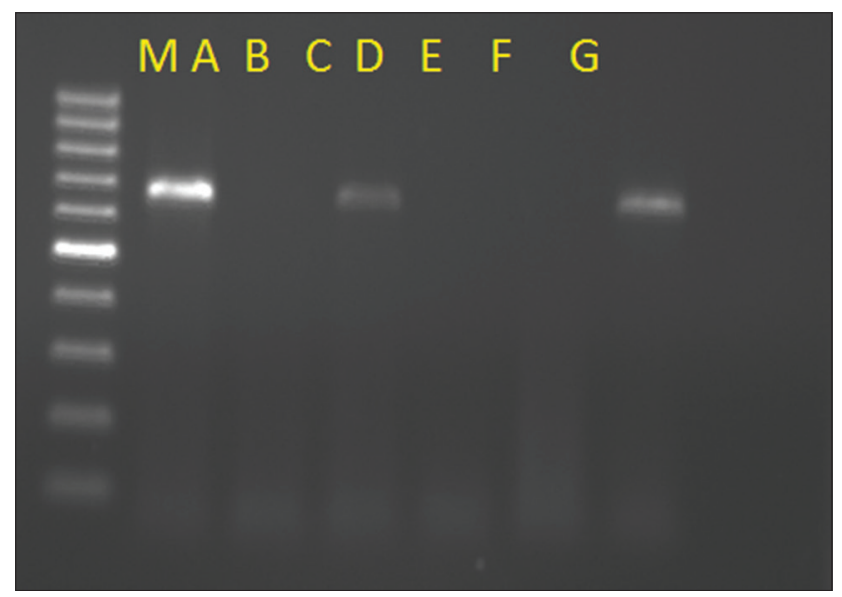

Figure-5: Agarose gel (1.5\%) electrophoresis showing 689 bp fragment of amplified $B$. bigemina in blood samples. Lane M: Molecular marker 100 bp, Lane A: Positive control, Lane B: Host leukocytes DNA, Lane C-F: Tested samples, Lane G: Negative control. 
Table-1: Hematological parameters in parasitologicaly positive (Group I), parasitologicaly negative (Group II) and healthy control (Group III) animals.

\begin{tabular}{|c|c|c|c|c|c|c|}
\hline \multirow[t]{2}{*}{ Group } & \multirow[t]{2}{*}{ Hb (g/dl) } & \multirow[t]{2}{*}{ TLC (per $\mu \mathrm{l})$} & \multicolumn{4}{|c|}{ DLC (\%) } \\
\hline & & & N (\%) & L (\%) & M (\%) & $E(\%)$ \\
\hline$I(n=7)$ & $3.5 * \pm 0.197$ & $12.44 \pm 0.464$ & $39.38 \pm 0.891$ & $58.39 \pm 0.234$ & $1.28 \pm 0.187$ & $0.70 \pm 0.138$ \\
\hline II $(n=8)$ & $7.79 \pm 0.252$ & $9.85 \pm 0.243$ & $37.90 \pm 0.128$ & $59.55 \pm 0.464$ & $1.38 \pm 0.494$ & $0.88 \pm 0.123$ \\
\hline III $(n=8)$ & $9.89 \pm 0.234$ & $10.77 \pm 0.470$ & $40.34 \pm 0.236$ & $57.14 \pm 0.125$ & $1.18 \pm 0.324$ & $0.78 \pm 0.112$ \\
\hline
\end{tabular}

*Statistically significant $(\mathrm{p}<0.05)$ as compare to Groups II and III. Hb=Hemoglobin, TLC=Total leucocytes count, DLC=Differential leucocyte count

direct method of identifying the parasite in Giemsastained blood smears is the gold standard test for diagnosis of babesiosis; however, this technique shows a low sensitivity in subclinical and chronic phase of the infection [22]. In addition, six cattle found positive by PCR were not having the predominant signs of babesiosis except weakness indicated the subclinical infections. Recently, PCR was employed to rule out the latent infection of the bovine babesiosis from Punjab [15]. Fahrimal et al. [23] and Zulfiqar et al. [24] reported greater sensitivity and specificity of PCR assays over the existing tests for diagnosis of bovine babesiosis.

Outbreaks were recorded in the month of June and July that are the favorable months for multiplication of the tick vector $(R$. $[B$.] microplus) identified in the present study. (R. (B.) microplus). Singh et al. [25] reported $R$. (Boophilus) microplus as predominant tick species in cattle and buffaloes of Punjab. There was a history of purchase of new animals in Sangrur district. Further, proper quarantine measures were not followed at the farm. It could be the possibility that newly purchased animals (in the carrier stage/incubation phase of disease) may be responsible for outbreak at the farm.

Livestock owners were advised to follow quarantine measures before intruding new animal into the herd. They were advised for tactical acaricidal treatments for effective tick control. Moreover, they were also advised for rotation of drugs and to administer proper dosage to prevent acaricidal resistance. Officials of Animal Husbandry Department were also informed about the outbreaks for implementation of control measures to prevent the spread of disease among other animals in the surrounding areas.

\section{Conclusion}

Two fatal outbreaks of babesiosis in cattle were diagnosed with application of conventional parasitological, hematological, and molecular diagnostic techniques. PCR was found to be far more sensitive in detecting the disease, especially in latent infections. Diseased animals were successfully treated and animal owners were advised to follow preventive measures for tick control.

\section{Authors' Contributions}

MSB, VM visited the farms for sample collection, carried out parasitological and hematological analysis in the laboratory. GF, PK and MSB carried out molecular analysis of samples. AS helped in planning, statistical analysis and supervised the research work. All authors drafted, revised and approved the final manuscript.

\section{Acknowledgment}

We are thankful to the Director of Research, Guru Angad Dev Veterinary and Animal Sciences University, Ludhiana, India and National Institute of Veterinary Epidemiology \& Disease Informatics (NIVEDI) (ICAR-11) for providing the necessary fund (Number F. N.6.15/PD_ADMAS/AICRP/ Punjab/2004-05/4055-4056) and facilities to carry out the research work.

\section{Competing Interests}

The authors declare that they have no competing interests.

\section{References}

1. Walker, G.K. and Edward, J.T. (1927) Some Diseases of Cattle in India. Government of India, Calcutta. p29.

2. McLeod, R. and Kristjanson, P. (1999) Final report of joint esys/ILRI/ACIAR Tick Cost project - Economic impact of ticks and TBD to livestock in Africa, Asia and Australia. International Livestock Research Institute (ILRI), Nairobi, Kenya. http://www.esys.com.au, http://www.cgiar.org/ilri. Accessed on 10-08-2016.

3. Sharma, A., Singla, L.D., Tuli, A., Kaur, P., Batth, B.K., Javed, M. and Juyal, P.D. (2013) Molecular prevalence of Babesia bigemina and Trypanosoma evansi in dairy animals from Punjab, India, by duplex PCR: A step forward to the detection and management of concurrent latent infections. BioMed. Res. Int. Available from: http://www.dx.doi. org/10.1155/2013/893862.

4. Jithendran, K.P. (1997) A note on haemoprotozoan parasites of cattle and buffaloes in Kangra valley of Himachal Pradesh. Indian J. Anim. Sci., 67: 207-208.

5. Singla, L.D., Singh, J. and Aulakh, G.S. (2002) Babesiosis in an unusual case of murrah buffalo with six functional teats. Buffalo Bull., 21: 55-58.

6. Rani, N.L., Sreedevi, C., Annapurna, P. and Kumar, K. (2010) Clinical management and haemato-biochemical changes in babesiosis in buffaloes. Buffalo Bull., 29: 92-94.

7. Patel, P.A, Modi, M.C., Chaudhary, P.M., Patel, S.P. and Joshi, A.H. (2011) A rare case of babesiosis in Mehsana buffalo. Int. J. Agro Vet. Med. Sci., 5: 383-384.

8. Karunakaran, S., Pillai, U., Narayana, K.A.M., Aswathy, G., Rajimon, K.T. and Sumangala, M. (2011) Babesia bigemina infection in a twenty day old calf. J. Indian Vet. Assoc. Kerala, 9: 49-50.

9. Venu, R., Sailaja, N., Rao, K.S., Jayasree, N. and Prasad, W.L.N. (2013) Babesia bigemina infection in a 14 day old Jersey crossbred calf: A case report. J. Parasit. 
Dis. DOI: 10.1007/s12639-013-0338-x.

10. Criado-Fornelio, A., Buling, A., Asenzo, G., Benitez, D., Florin-Christensen, M., Gonzalez-Oliva, A., Henriques, G., Silva, M.S., Alongi, A., Agnone, A., Torina, A. and Madruga, C.R. (2009) Development of fluorogenic probebased PCR assays for the detection and quantification of bovine piroplasmids. Vet. Parasitol., 162: 200-206.

11. Aulakh, G.S., Singla, L.D., Kaur, P. and Alka, A. (2005) Bovine babesiosis due to Babesia bigemina: Haematobiochemical and therapeutic studies. Indian $J$. Anim. Sci., 75: 617-622.

12. Ananda, K.J., D'Souza, P.E. and Puttalakshmamma, G.C. (2009) Prevalence of haemo-protozoan diseases in crossbred cattle in Bangalore North. Vet. World, 2: 15-16.

13. Chaudhri, S.S., Bisla, R.S., Bhanot, V. and Singh, H. (2013) Prevalence of haemoprotozoan infections in pyretic dairy animals of eastern Haryana. Indian J. Anim. Res., 47: 344-347

14. Shams, S., Ayaz, S., Ali, I., Khan, S., Gul, I., Gul, N. and Khan, S.N. (2013) Sensitivity and specificity of PCR \& microscopy in detection of Babesiosis in domesticated cattle of Khyber Pakhtunkhwa, Pakistan. Int. J. Adv. Res. Technol., 2(5): 37-41.

15. Sharma, A., Singla, L.D., Ashuma, Batth, B.K. and Kaur, P. (2016) Clinicopatho-biochemical alterations associated with subclinical babesiosis in dairy animals. J. Arthropod Borne Dis., 10(2): 259-267.

16. Miranpuri, G.S. (1979) Tick taxonomy in India - A review (including notes on their biology, ecology, geographical distribution, host-relationship, ticks and tick-borne diseases and keys for species identification). Paper Presented at Workshop at Advances in Insect Taxonomy in India and the Orient, Held at Manali, Himachal Pradesh, from October, 9 to 12 , India.

17. Ellis, J., Hefford, C., Baverstock, P.R., Dalrymple, B.P. and Johnson, A.M. (1992) Ribosomal DNA sequence comparison of Babesia and Theileria. Mol. Biochem. Parasitol., 54: 87-95.

18. Wadhwa, D.R., Pal, B. and Mandial, R.K. (2008) Epidemiological and clinico-therapeutic study of babesiosis in cattle. Indian J. Vet. Res., 17: 22-24.

19. Jyothisree, C., Naik, S. and Samatha, V. (2013) A study on prevalence and clinico-therapeutic management of babesiosis in H.F. Crossbred cattle in Anantapur district of Andhra Pradesh. Int. J. Food Agric. Vet. Sci., 3: 88-91.

20. Georgi, J.R., Georgi, M.E. and Theodrides, V.J. (1990) Parasitology for Veterinarians. $5^{\text {th }}$ ed. W. B. Saunders Company, Harcourt Brace Jovanovich, Inc., Philadelphia, PA.

21. Achutan, H.N., Mahadevan, S. and Laliltha, C.M. (1980) Observation on the transmission of Babesia bigemina and Babesia canis infection, through inoculation. Cheiron, 9: 131-33.

22. Terkawi, M.A., Thekisoe, O.M., Katsande, C., Latiff, A.A., Mans, B.J., Matthee, O., Mkize, N., Mabogoane, N., Marais, F., Yokoyama, N., Xuan, X. and Igarashi, I. (2011) Serological survey of Babesia bovis and Babesia bigemina in cattle in South Africa. Vet. Parasitol., 182: 337-342.

23. Fahrimal, Y., Goff, W.L. and Jasmer, D.P. (1992) Detection of Babesia bovis carrier cattle by using polymerase chain reaction amplification of parasite DNA. J. Clin. Microbiol., 30: 1374-1379.

24. Zulfiqar, S., Shahnawaz, S., Ali, M., Bhutta, A.M., Iqbal, S., Hayat, S., Qadir, S., Latif, M., Kiran, N., Saeed, A., Ali, M. and Iqbal, F. (2012) Detection of Babesia bovis in blood samples and its effect on the hematological and serum biochemical profile in large ruminants from Southern Punjab. Asian Pac. J. Trop. Biomed., 2: 104-108.

25. Singh, A.P., Singla, L.D. and Singh, A. (2000) A study on the effects of macroclimatic factors on the seasonal population dynamics of Boophilus micropus (Canes, 1888) infesting the cross-bred cattle of Ludhiana district. Int. J. Anim. Sci., 15: 29-31. 